\title{
Curcumin Pharmacokinetic and Pharmacodynamic Evidences in Streptozotocin-Diabetic Rats Support the Antidiabetic Activity to Be via Metabolite(s)
}

\author{
Vânia Ortega Gutierres, ${ }^{1}$ Michel Leandro Campos, ${ }^{2}$ \\ Carlos Alberto Arcaro, ${ }^{1}$ Renata Pires Assis, ${ }^{1}$ Helen Mariana Baldan-Cimatti, ${ }^{2}$ \\ Rosângela Gonçalves Peccinini, ${ }^{2}$ Silvia Paula-Gomes, ${ }^{3}$ Isis Carmo Kettelhut, ${ }^{3}$ \\ Amanda Martins Baviera, ${ }^{1}$ and Iguatemy Lourenço Brunetti ${ }^{1}$

\footnotetext{
${ }^{1}$ Department of Clinical Analysis, School of Pharmaceutical Sciences, São Paulo State University (UNESP), Rodovia Araraquara-Jaú Km 01, 14801-902 Araraquara, SP, Brazil

${ }^{2}$ Department of Natural Active Principles and Toxicology, School of Pharmaceutical Sciences, São Paulo State University (UNESP), Rodovia Araraquara-Jaú Km 01, 14801-902 Araraquara, SP, Brazil

${ }^{3}$ Department of Biochemistry and Immunology, School of Medicine, University of São Paulo (USP), Avenida Bandeirantes 3900, 14040-900 Ribeirão Preto, SP, Brazil
}

Correspondence should be addressed to Iguatemy Lourenço Brunetti; brunetti@fcfar.unesp.br

Received 15 December 2014; Revised 16 March 2015; Accepted 17 March 2015

Academic Editor: Yong H. Liao

Copyright (C) 2015 Vânia Ortega Gutierres et al. This is an open access article distributed under the Creative Commons Attribution License, which permits unrestricted use, distribution, and reproduction in any medium, provided the original work is properly cited.

\begin{abstract}
This study measures the curcumin concentration in rat plasma by liquid chromatography and investigates the changes in the glucose tolerance and insulin sensitivity of streptozotocin-diabetic rats treated with curcumin-enriched yoghurt. The analytical method for curcumin detection was linear from 10 to $500 \mathrm{ng} / \mathrm{mL}$. The $C_{\max }$ and the time to reach $C_{\max }\left(t_{\max }\right)$ of curcumin in plasma were $3.14 \pm 0.9 \mu \mathrm{g} / \mathrm{mL}$ and 5 minutes (10 mg/kg, i.v.) and $0.06 \pm 0.01 \mu \mathrm{g} / \mathrm{mL}$ and 14 minutes $(500 \mathrm{mg} / \mathrm{kg}$, p.o.). The elimination half-time was $8.64 \pm 2.31$ (i.v.) and $32.70 \pm 12.92$ (p.o.) minutes. The oral bioavailability was about $0.47 \%$. Changes in the glucose tolerance and insulin sensitivity were investigated in four groups: normal and diabetic rats treated with yoghurt (NYOG and DYOG, resp.) and treated with $90 \mathrm{mg} / \mathrm{kg} /$ day curcumin incorporated in yoghurt (NC90 and DC90, resp.). After 15 days of treatment, the glucose tolerance and the insulin sensitivity were significantly improved in DC90 rats in comparison with DYOG, which can be associated with an increase in the AKT phosphorylation levels and GLUT4 translocation in skeletal muscles. These findings can explain, at least in part, the benefits of curcumin-enriched yoghurt to diabetes and substantiate evidences for the curcumin metabolite(s) as being responsible for the antidiabetic activity.
\end{abstract}

\section{Introduction}

Curcumin (diferuloylmethane) is a yellow pigment isolated from the dried rhizomes of Curcuma longa L. (turmeric). In Asian countries, turmeric is largely used as a dietary spice. Furthermore, traditional Indian and Chinese medicines have used turmeric for the treatment of a diversity of diseases [1]; curcumin has been cited as the main phytochemical responsible for the turmeric beneficial effects. Crescent attention has been given to understand the role of curcumin in the prevention and treatment of various chronic diseases, such as cancer $[2,3]$, cardiovascular diseases [4], and metabolic disturbances, including obesity [5] and diabetes mellitus [6].

A wide range of biological activities has been attributed to curcumin; however the translation of its experimental biological benefits into clinical trials is difficult due to the low bioavailability of this pigment when administered orally, observed in both rodents [7] and humans [8], which is explained by its poor absorption due to the low solubility in water, limited tissue distribution, and rapid rate of 
metabolism in liver and intestine followed by the rapid excretion from the body [9]. So the low bioavailability of curcumin appears as a major barrier to reach its adequate circulating levels related to desirable pharmacodynamic actions, hindering its clinical approval as a therapeutic agent for several diseases.

Attempting to overcome this situation, several vehicles and associations with curcumin have been tested, such as curcumin-loaded nanoparticles [10], complexing with phospholipids [2], microemulsifying [11], and association with drug bioenhancers, for example, piperine [12], among others [13]. Previous study from our laboratory [14] showed that curcumin incorporated in yoghurt improved several physiological and biochemical parameters of streptozotocin- (STZ-) diabetic rats treated for 31 days: the food and water intake and the urinary volume were decreased and the body weight gain was increased; the plasma levels of glucose, triglycerides, and transaminases and the urinary levels of glucose, urea, and protein in urine were decreased, when compared with nontreated diabetic rats. These biomarkers were not changed in nondiabetic rats treated with curcumin-enriched yoghurt. With the objective to increase the antidiabetic activity of curcumin, our laboratory recently investigated its coadministration with piperine, which inhibits the biotransformation processes occurring in liver and intestine, increasing the bioavailability of drugs; notably, the treatment of STZdiabetic rats with both curcumin and piperine in yoghurt for 45 days did not change or even nullified, in the dosedependent way, the antidiabetic and antioxidant activities of curcumin [15], suggesting that the biotransformation is important to these pharmacological actions of curcumin. In light of these data, the investigation of the pharmacokinetic profile of curcumin when administered with yoghurt in diabetic animals became interesting which, as far as we know, has not yet been described.

The aim of this study was to evaluate the pharmacokinetics of curcumin in diabetic rats when administered intravenously and orally (incorporated in yoghurt) and also to investigate the changes in the glucose tolerance and insulin sensitivity of diabetic rats after acute (1 day) and subchronic (15 days) treatments with curcumin incorporated in yoghurt.

\section{Material and Methods}

2.1. Chemical and Reagents. Curcumin $(\geq 77 \%, 28260$, FlukaSigma Aldrich, St. Louis, MO, USA) and analytical standard curcumin ( $\geq 98.0 \%$, 08511, Fluka-Sigma Aldrich, St. Louis, MO, USA), streptozotocin (STZ, Sigma Aldrich, St. Louis, MO, USA), dinitrophenol, and dimethyl sulfoxide (DMSO) were obtained from Sigma Aldrich (St. Louis, MO, USA); ketamine and xylazine were obtained from Agener União (Embu-Guaçu, SP, Brazil); acetonitrile and methanol (HPLC grade) were obtained from J. T. Baker (Mexico City, Mexico); acetic acid was obtained from Qhemis (Indaiatuba, SP, Brazil); and insulin (Biohulin NU-100; 100 units $/ \mathrm{mL}$ ) was obtained from Biobras (Montes Claros, MG, Brazil). Sodium hydroxide was purchased from Cetus (Santo Amaro, SP, Brazil) and plain yoghurt from Nestlé (Araras, SP, Brazil).
Water was purified by a Millipore system (EMD Millipore, Darmstadt, Germany).

2.2. HPLC Analysis of Curcumin. The high performance liquid chromatography (HPLC) system consisted of a Waters $600 \mathrm{E}$ with a $50 \mu \mathrm{L}$ sample loop coupled to UV-Vis detector (Waters 2487) set to $420 \mathrm{~nm}$ and a computer system for data acquisition (Empower software, Waters) was used. The separation was achieved using a reversed phase Symmetry $\mathrm{C}_{18}$ column $(4.6 \times 250 \mathrm{~mm}$, particle size $5 \mu \mathrm{m})$. Mobile phase consisting of methanol, acetonitrile, and $5 \%$ acetic acid $(35: 50: 15, \mathrm{v} / \mathrm{v})$ was employed at a flow rate of $1.0 \mathrm{~mL} / \mathrm{min}$.

\subsection{Preparation of the Standard Solutions and Quality Control} of Samples. Standard solutions of curcumin ( $\geq 98 \%$, 08511, Fluka-Sigma Aldrich, St. Louis, MO, USA) were prepared in methanol at six concentration levels $(0.10,0.25,0.75,1.25,2.5$, and $5 \mu \mathrm{g} / \mathrm{mL}$ ). These solutions were diluted in plasma to reach the final plasma concentrations of $10,25,75,125,250$, and $500 \mathrm{ng} / \mathrm{mL}$.

2.4. Sample Preparation. An aliquot of $500 \mu \mathrm{L}$ of rat plasma (blank) or $500 \mu \mathrm{L}$ of rat plasma containing curcumin (concentrations as described in Section 2.3) were mixed with $10 \mu \mathrm{L}$ of $0.01 \mathrm{M} \mathrm{NaOH}$ and $40 \mu \mathrm{L}$ of acetonitrile containing $200 \mu \mathrm{g} / \mathrm{mL}$ dinitrophenol; dinitrophenol was used as internal standard (IS). The mixture was vortexed (30 seconds) and $1000 \mu \mathrm{L}$ of ethyl acetate was added and vortexed again, followed by centrifugation at $1000 \times \mathrm{g}$ for 15 minutes at $10^{\circ} \mathrm{C}$. After that, $500 \mu \mathrm{L}$ of supernatant was transferred to a new clean plastic microtube and evaporated under vacuum for 15 minutes at $37^{\circ} \mathrm{C}$ in a Mini Vac Sample Concentrator RangeGenevac. Lastly, the dry sample was reconstituted by $125 \mu \mathrm{L}$ of methanol and injected into the HPLC system.

2.5. Method Validation. In order to determine the confidence limits of the bioanalytical method, the validation was performed based on the RDC-27/2012 from Agência Nacional de Vigilância Sanitária (ANVISA, Brazil) and the Guidance for Industry: Bioanalytical Method Validation 2001 from Food and Drug Administration (FDA, USA). The analytical methodology was validated regarding selectivity, linearity, accuracy, precision, limit of detection (LOD), lower limit of quantitation (LLOQ), recovery, and stability.

The selectivity evaluation of the method was performed by the analysis of a blank plasma sample in order to determine the presence of interfering peaks in curcumin and IS retention times.

Linearity was achieved by plotting the curcumin/IS ratio versus nominal concentrations. The acceptance criteria for linearity were accuracy as percentage of the nominal concentration (\%) between 85 and 115\%, except at the LLOQ, where it can be between 80 and $120 \%$ and linear regression coefficient ( $r$ ) higher than 0.98 .

Precision and accuracy were evaluated together at four concentration levels or quality controls (QC): high-QC (HQC) $400 \mathrm{ng} / \mathrm{mL}$, medium-QC (MQC) $125 \mathrm{ng} / \mathrm{mL}$, lowerQC (LQC) $25 \mathrm{ng} / \mathrm{mL}$, and the LLOQ-QC $10 \mathrm{ng} / \mathrm{mL}$. The assay 
was carried out in the same day (intraday, $n=5$ ) and in three different days (interday, $n=15$ ). The acceptance criterion for precision was a coefficient of variation (\%) less than $15 \%$, except at the LLOQ where it can be less than $20 \%$. The accuracy acceptance criterion was a percentage of the nominal concentration (\%) between 85 and 115\%, except at the LLOQ where it can be between 80 and $120 \%$.

The recovery test, which determines the extraction procedure efficiency, was achieved comparing extracted samples to nonextracted samples (100\%) of curcumin in HQC and LQC.

In order to determine whether the sample can be stored in specific conditions, the stability studies were performed. Plasma aliquots were prepared at concentrations of 25 and $400 \mathrm{ng} / \mathrm{mL}$ in triplicate and analyzed according to the following conditions: bench-top stability, where the samples stay at room temperature $\left(30^{\circ} \mathrm{C}\right)$ for $4 \mathrm{~h}$; postprocessing stability, where samples stay at room temperature $\left(30^{\circ} \mathrm{C}\right)$ for $4 \mathrm{~h}$ after extraction; freeze-thaw stability, where samples were frozen at $-20^{\circ} \mathrm{C}$ and thawed at room temperature over three cycles during 72 hours; long-term stability, where samples were frozen at $-20^{\circ} \mathrm{C}$ for seven days. After these conditions, samples were analyzed and compared with the results obtained from freshly prepared and analyzed samples.

2.6. Animals. Male Wistar rats (Rattus norvegicus) weighing $140-160$ g (6 weeks) were maintained under environmentally controlled conditions of temperature $\left(23 \pm 1^{\circ} \mathrm{C}\right)$ and humidity $(55 \pm 5 \%)$ and with a $12 \mathrm{~h}$ light/dark cycle, having free access to water and normal lab chow diet (Purina Evialis do Brasil Nutrição Animal Ltda., SP, Brazil). Before the beginning of the experiments, the animals were maintained under these conditions for at least 5 days. The experiments were conducted during the light phase and the experimental protocol was approved by the Committee for Ethics in Animal Experimentation of the School of Pharmaceutical Sciences, UNESP, Araraquara (resolution number 37/2012).

2.7. Induction of the Experimental Diabetes Mellitus. Experimental diabetes mellitus was induced by a single intravenous injection of STZ (40 mg/kg b.w.) dissolved in $0.01 \mathrm{M}$ citrate buffer ( $\mathrm{pH} 4.5)$, in previously $14 \mathrm{~h}$ fasted rats. Normal rats received only citrate buffer. Four days after STZ administration, diabetic rats with postprandial glycemia values of approximately $400 \mathrm{mg} / \mathrm{dL}$ were used in the experiments. Plasma glucose levels were determined by the glucose oxidase method [16] using commercial kit (Labtest Diagnostica SA, Brazil).

2.8. Preparation of Curcumin-Enriched Yoghurt. Curcumin ( $\geq 77 \%$, 28260, Fluka-Sigma Aldrich, St. Louis, MO, USA) was mixed with $0.5 \mathrm{~mL}$ of plain yoghurt, in the doses of 45 or $500 \mathrm{mg} / \mathrm{kg}$ b.w., with a homogenizer (Metabo, Marconi, Piracicaba, SP, Brazil) operating at 27,000 rpm for 90 seconds at a controlled temperature of $25^{\circ} \mathrm{C}$.

2.9. Pharmacokinetics (PK) of Curcumin in Diabetic Rats. Twenty-five diabetic rats (weighing 150-200 g) were divided into two groups: intravenous (i.v.) group $(n=10)$, of which animals were treated with $10 \mathrm{mg} / \mathrm{kg}$ of curcumin $(16 \mathrm{mg} / \mathrm{mL}$ in DMSO), and the oral group $(n=15)$, of which animals were treated with $500 \mathrm{mg} / \mathrm{kg}$ of curcumin (single dose) incorporated in $0.5 \mathrm{~mL}$ of yoghurt.

Twenty-four hours before the curcumin administration, the animals were submitted to vein and/or artery catheter implantation. These catheters were used to drug administration or to serial blood collections [17]. Eight hours before the curcumin administration, the animals were deprived of food. The sampling times were 5, 10, 20, 30, 45, and 60 minutes after the oral administration and 2.5, 5, 7.5, 10, 20, 30, and 45 minutes after the i.v. administration. Both administrations were performed over a short period of time.

The curcumin PK parameters were calculated based on the concentration in plasma versus time curves. The half-life of elimination $\left(t_{1 / 2}\right)$ was calculated by the graphic method and the half-life of absorption was calculated by the residues method. The constants of absorption $\left(k_{a}\right)$ and elimination $\left(k_{\mathrm{el}}\right)$ were calculated by the equation $0.693 / t_{1 / 2}$, where $t_{1 / 2}$ is the half-life of absorption or elimination, respectively. The area under the curve (AUC) of the plasma concentration versus time profile from time zero to the last sampling time $\left(\mathrm{AUC}_{0-t}\right)$ was calculated by the trapezoidal rule. The area under the curve from time zero extrapolated to infinity $\left(\mathrm{AUC}_{0-\infty}\right)$ was calculated by the equation $\mathrm{AUC}_{0-\infty}=\mathrm{AUC}_{0-t}$ $+C_{\mathrm{pn}} / k_{\mathrm{el}}$ (where $C_{\mathrm{pn}}$ is the last plasma concentration determined and $k_{\mathrm{el}}$ is the elimination constant). The $\mathrm{AUC}_{0-\infty}$ was used for the calculation of the total clearance $(\mathrm{Cl}=$ dose/ $\left.\mathrm{AUC}_{0-\infty}\right)$, and the distribution volume $\left(V_{d}\right)$ was calculated using the equation $V_{d}=\mathrm{Cl} / k_{\mathrm{el}}$. The mean residence time (MRT) was estimated from AUMC/AUC, where AUMC is area under the first moment curve. The oral bioavailability $(F)$ of curcumin was calculated by the relation between the AUC obtained in the oral administration and the AUC obtained in the intravenous administration. The maximum plasma concentration $\left(C_{\max }\right)$ was obtained from the experimental data as well as the time of the occurrence of $C_{\max }\left(t_{\max }\right)$.

\subsection{Pharmacodynamics (PD) of Curcumin Administered with Yoghurt}

2.10.1. Treatment of Animals. Forty rats were divided into four groups: normal rats treated with yoghurt (NYOG) or with $45 \mathrm{mg} / \mathrm{kg}$ curcumin-enriched yoghurt twice a day (NC90); diabetic rats treated with yoghurt (DYOG) or with $45 \mathrm{mg} / \mathrm{kg}$ curcumin-enriched yoghurt twice a day (DC90). Normal and diabetic rats were treated by gavage at 08:00 $\mathrm{h}$ and 17:00 h, for 15 days. Curcumin incorporated in yoghurt (as described in Section 2.8) was administered as a half dose in $0.5 \mathrm{~mL}$, totaling $1.0 \mathrm{~mL}$ yoghurt/rat/day of treatment. Control rats received only yoghurt. Glucose and insulin tolerance tests were performed after 1 and 15 days of treatment. Changes in the insulin signaling pathway (total protein content and phosphorylation levels in serine-473 residue of AKT or protein kinase B) and in the content of glucose transporter type 4 (GLUT4) in plasma membrane were also investigated in gastrocnemius muscles from NYOG, NC90, DYOG, and DC90 rats treated for 15 days and submitted to a glucose oral overload (as described in Section 2.10.2). 
2.10.2. Oral Glucose Tolerance Test (OGTT). OGTT was performed in $14 \mathrm{~h}$ fasted rats. A glucose solution $(2.5 \mathrm{~g} / \mathrm{kg}$ b.w. $)$ was administered orally, and blood samples were collected from the tip of the tail before $(t=0)$ and $15,30,45,60,75$, 90,105 , and 120 minutes after the glucose loading. Results were expressed as $\mathrm{mg} / \mathrm{dL}$ and the area under the curve (AUC, $\mathrm{g} / \mathrm{dL} / 120 \mathrm{~min}$ ) was calculated.

2.10.3. Insulin Tolerance Test (ITT). For ITT, $6 \mathrm{~h}$ fasted rats received a single intraperitoneal injection of human recombinant insulin (1.5 U/kg b.w.), and blood samples were collected before $(t=0)$ and $5,10,15,20,25$, and 30 minutes after the insulin administration for the plasma glucose measurement. Results were expressed as mg/dL. For the estimation of the insulin sensitivity, the constant rate for glucose disappearance $\left(k_{\mathrm{itt}}, \% / \mathrm{min}\right)$ was calculated using the equation $k_{\mathrm{itt}}=0.693 / t_{1 / 2}$, where $t_{1 / 2}$ represents the half-life of plasma glucose concentration calculated from the slope of least squares analysis in the interval of time in which glycemia declines linearly after the insulin administration [18].

2.10.4. Western Blotting Analysis. Concerning sample preparation for AKT protein content and phosphorylation levels, gastrocnemius muscles were homogenized in $50 \mathrm{mM}$ Tris-HCl buffer ( $\mathrm{pH}$ 7.4) containing $150 \mathrm{mM} \mathrm{NaCl}, 1 \mathrm{mM}$ ethylenediaminetetraacetic acid (EDTA), 1\% Triton X-100, $1 \%$ sodium deoxycholate, $1 \%$ SDS, $10 \mathrm{mM}$ sodium pyrophosphate, $100 \mathrm{mM}$ sodium fluoride, $10 \mathrm{mM}$ sodium orthovanadate, $5 \mu \mathrm{g} / \mathrm{mL}$ aprotinin, $1 \mu \mathrm{g} / \mathrm{mL}$ leupeptin, and $1 \mathrm{mM}$ phenylmethylsulfonyl fluoride (PMSF). The homogenates were centrifuged at $15,500 \times \mathrm{g}$ at $4^{\circ} \mathrm{C}$ for 40 minutes and the supernatant was used for analysis. Protein levels were determined using bovine serum albumin as standard [19].

Concerning sample preparation for GLUT4 content in plasma membrane, gastrocnemius muscles were homogenized in $50 \mathrm{mM}$ Tris- $\mathrm{HCl}$ buffer ( $\mathrm{pH} 8.0$ ) containing $0.1 \%$ NP-40, $0.5 \mathrm{mM}$ dithiothreitol (DTT), and the same proteases and phosphatases inhibitors used in the above buffer. The homogenates were centrifuged at $1,000 \times \mathrm{g}$ at $4^{\circ} \mathrm{C}$ for 10 minutes. Precipitates were washed twice with the same buffer above described without NP-40 and centrifuged at the same conditions. Precipitates were added in buffer containing $1 \% \mathrm{NP}-40$ and then centrifuged at $15,500 \times \mathrm{g}$ at $4^{\circ} \mathrm{C}$ for 20 minutes; the supernatants were considered the plasma membrane fraction [20].

Supernatants (for AKT and GLUT4 studies) were prepared with sample buffer ( $125 \mathrm{mM}$ Tris- $\mathrm{HCl}, 20 \%$ glycerol, $4 \%$ SDS, 100 mM DTT, 0.02\% bromophenol blue, $\mathrm{pH} 6.8$ ); equal amounts of protein $(20 \mu \mathrm{g})$ were subjected to SDSPAGE analysis on $8 \%$ acrylamide gels [21] and electroblotted onto nitrocellulose membranes [22].

After blocking, proteins were detected by overnight incubation at $4^{\circ} \mathrm{C}$ with specific primary antibodies: antiAKT (1:500, Cell Signaling, Danvers, MA, USA), antiphospho-[Ser-473]-AKT (1:500, Cell Signaling, Danvers, MA, USA), and anti-GLUT4 (1:1,000, Santa Cruz Biotechnology, Santa Cruz, CA, USA). Anti- $\beta$-actin $(1: 1,000$, Santa Cruz Biotechnology, Santa Cruz, CA, USA) was used as internal control. Primary antibodies were detected by

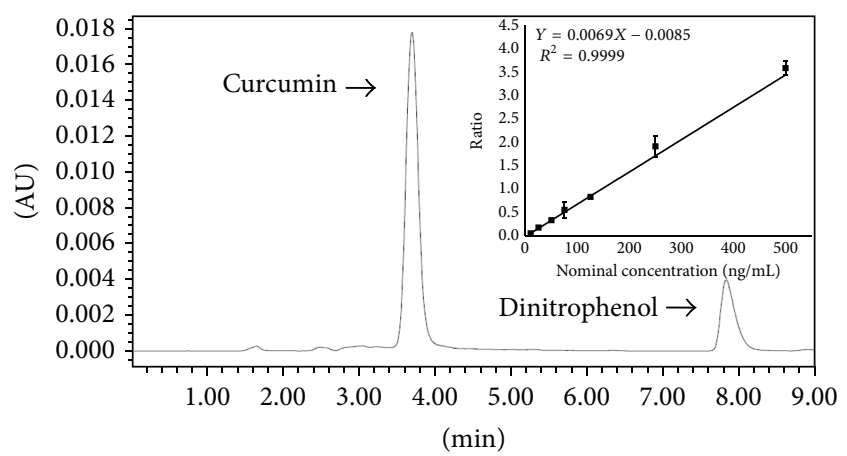

FIGURE 1: Chromatogram of plasma analysis containing $25 \mathrm{ng} / \mathrm{mL}$ curcumin and IS $(5.3 \mu \mathrm{g} / \mathrm{mL}$ dinitrophenol) at $420 \mathrm{~nm}$ and the linearity of the bioanalytical method.

peroxidase-conjugated secondary antibodies (Cell Signaling, Danvers, MA, USA) and visualized with enhanced chemiluminescence reagents (SuperSignal West Pico Chemiluminescent Substrate, Thermo Scientific, Waltham, MA, USA) and detected with C-Digit Blot Scanner (LI-COR, Lincoln, NE, USA). Band intensities were read and analyzed with the LICOR Image Studio 4.0 Program.

2.11. Statistical Analysis. Data were expressed as mean \pm standard error of mean (SEM). One-way analysis of variance (ANOVA) followed by Student-Newman-Keuls test was used to compare the intergroup differences and of the AUC. Differences were considered significant at $P<0.05$. Statistical analyses were performed using the program Graphpad Instat 3.05 (GraphPad Software, USA).

\section{Results}

3.1. Method Validation. As observed in the chromatogram (Figure 1), curcumin and IS showed retention times of 4 and 8 minutes, respectively, which shows plasma containing curcumin $(25 \mathrm{ng} / \mathrm{mL})$ and IS $(5.3 \mathrm{ng} / \mathrm{mL})$ at $420 \mathrm{~nm}$. The selectivity assay showed no interfering peaks of the biological matrix. This method was validated using four quality control levels of the calibration curve. The obtained linearity equation was $y=0.0069-0.0085 x$ and linear regression coefficient was $r=0.9999$. Each curve concentration level matched to the accuracy acceptance criteria, of which accuracy range was $87.88-105.82 \%$. All precision and accuracy results are within the acceptance criteria (Table 1). The intraday and interday precisions were no more than $13.52 \%$ and $12.46 \%$, respectively, while the intraday and interday accuracies were between 86.05 and $113.59 \%$ and between 89.65 and $98.74 \%$, respectively. The obtained recovery for curcumin was $67 \pm$ 9.78\%; however, there is no acceptance criterion to recovery, since the recovery reproducibility is good enough to stay within the accuracy and precision acceptance criteria. The stability study indicated that curcumin is stable at the evaluated conditions, considering that it has not failed in any of the tests (Table 2). 
TABLE 1: Intraday $(n=5)$ and interday $(n=5)$ accuracy and precision of the bioanalytical method to quantify curcumin in plasma.

\begin{tabular}{lcc}
\hline $\begin{array}{l}\text { Nominal } \\
\text { concentration } \\
(\mathrm{ng} / \mathrm{mL})\end{array}$ & Accuracy $(\%)$ & Precision CV (\%) \\
\hline $\begin{array}{l}\text { Intraday } \\
10\end{array}$ & 113.59 & 13.52 \\
25 & 86.05 & 11.03 \\
125 & 92.40 & 2.67 \\
400 & 112.88 & 8.68 \\
Interday & & \\
10 & 89.65 & 7.58 \\
25 & 91.85 & 12.46 \\
125 & 94.52 & 8.57 \\
400 & 98.74 & 9.62 \\
\hline
\end{tabular}

3.2. PK Profile of Curcumin. PK profile was evaluated after a single administration of $10 \mathrm{mg} / \mathrm{kg}$ b.w. of curcumin in DMSO (i.v.) and $500 \mathrm{mg} / \mathrm{kg}$ b.w. of curcumin incorporated in yoghurt (p.o.). Curcumin plasma concentration versus time profiles can be seen in Figure 2. Concentration values were best-fitted by a one-compartmental model. Maximum plasma curcumin concentration occurred in about 14 minutes after the oral administration. The intravenously administered curcumin showed extrapolated $C_{\max }$ of $3.14 \pm 0.90 \mu \mathrm{g} / \mathrm{mL}$, whereas oral administration with a dose 50-fold higher showed $0.06 \pm 0.01 \mu \mathrm{g} / \mathrm{mL}$ (Table 3).

The areas under curve $\left(\mathrm{AUC}_{0-t}\right)$ were $12.27 \pm$ $2.75 \mu \mathrm{g} / \mathrm{mL} / \mathrm{min}$ for intravenous administration and $1.89 \pm 0.25 \mu \mathrm{g} / \mathrm{mL} / \mathrm{min}$ for oral administration, of which doses were $10 \mathrm{mg} / \mathrm{kg}$ and $500 \mathrm{mg} / \mathrm{kg}$, respectively (Table 4).

Although the $\mathrm{Cl}$ was not different between these administration routes, $V_{d}$ for oral administration was higher than $V_{d}$ for i.v. administration, leading to an increase in the curcumin half-life through oral route (Table 4).

3.3. Glucose Tolerance and Insulin Sensitivity after Short-and Long-Term Treatment of Diabetic Rats with Curcumin. In the OGTT, the hyperglycemia peek developed by DYOG group 30 minutes after the glucose overload was approximately 2fold higher $(P<0.001)$ than NYOG, in the 1st (Figures 3(a) and 3(b)) or 15th day (Figures 3(c) and 3(d)) of experiment. After 120 minutes, DYOG did not correct the glycemia with the same efficiency of that observed in NYOG, this last group returning the glycemia to basal values, in the 1st or 15 th day of experiment. Consequently, the glucose tolerance was significantly impaired in DYOG rats when compared with NYOG rats (Figure 3, AUC, 1 and 15 days). Insulin sensitivity was progressively decreased in diabetic rats, since after insulin administration the DYOG group was not able to reduce the glycemia levels as efficiently as NYOG, in both 1st

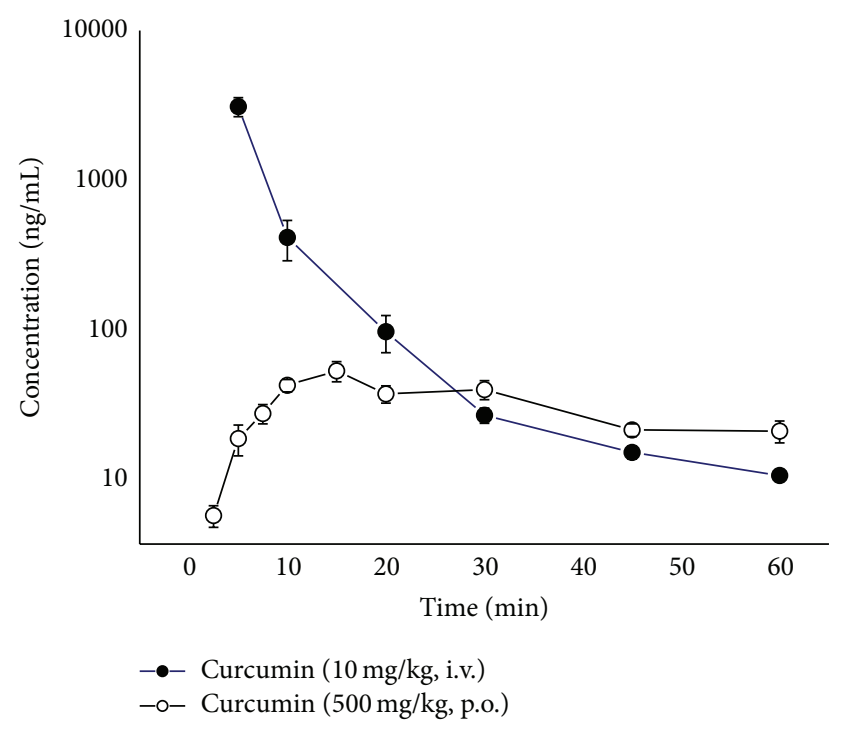

FIgURe 2: Plasma curcumin concentrations versus time curves in STZ-diabetic rats. Values are expressed as means \pm SEM.

day (Figures 4(a) and 4(b)) and 15th day (Figures 4(c) and $4(d))$ of experiment.

The treatment of normal, nondiabetic rats with curcumin (NC90) did not change the glucose tolerance in comparison to normal rats treated only with yoghurt (NYOG), after 1 (Figure 3(b)) or 15 days (Figure 3(d)) of treatment (Figure 3). The ITT was also performed in normal rats after 1 and 15 days of curcumin treatment, and the constant rate for glucose disappearance $\left(k_{\mathrm{itt}}\right)$ was calculated to estimate the insulin sensitivity. There were no statistical differences in the $k_{\text {itt }}$ values between NYOG and NC90 rats after 1 or 15 days of treatment (Figure 4, inserted table, $\mathrm{N}$ groups).

Although DYOG and DC90 groups showed similar values of hyperglycemia peek after the glucose overload, diabetic rats treated with curcumin for 1 day showed a better capacity to reduce the glycemia after 105 and 120 minutes of the glucose overload $(P<0.05$, Figure 3(a)); however the glucose tolerance was not yet different when DYOG and DC90 were compared (Figure 3, AUC, 1 day). The insulin sensitivity was not also different for the comparison between DYOG and DC90 after 1 day of treatment, since these groups showed similar rates of glucose disappearance after insulin administration and similar $k_{\mathrm{itt}}$ values (Figure 4, inserted table, D groups).

After 15 days of treatment, the beneficial effects of curcumin on glucose metabolism of diabetic rats become evident. In the OGTT, after 60 minutes of the glucose overload, DC90 rats were able to reduce glycemia more efficiently than DYOG (Figure 3(c)); consequently, the glucose tolerance was significantly improved in DC90 group in comparison with DYOG $(P<0.05$, Figure 3, AUC, 15 days). The treatment of diabetic rats with curcumin for 15 days reduced the fall in the insulin sensitivity, and the $k_{\mathrm{itt}}$ values of DC90 rats were 2 -fold increased $(P<0.01)$ when compared with DYOG (Figure 4 , inserted table, $\mathrm{D}$ groups). 
TABLE 2: Stability of curcumin in plasma under different conditions of storage, temperature, and time intervals $(n=3)$.

\begin{tabular}{lcccr}
\hline \multirow{2}{*}{ Sample condition } & & \multicolumn{2}{c}{ Curcumin nominal concentration } \\
& Accuracy $(\%)$ & $25 \mathrm{ng} / \mathrm{mL}$ & & \multicolumn{2}{c}{$400 \mathrm{ng} / \mathrm{mL}$} \\
Bench-top $\left(30^{\circ} \mathrm{C}, 4 \mathrm{~h}\right)$ & 91.85 & Precision CV (\%) & Accuracy $(\%)$ & 105.90 \\
Postprocessing $\left(30^{\circ} \mathrm{C}, 4 \mathrm{~h}\right)$ & 88.45 & 7.90 & 101.56 & 12.50 \\
Freeze-thaw $\left(-20^{\circ} \mathrm{C}, 72 \mathrm{~h}\right)$ & 89.34 & 5.40 & 99.47 & 13.40 \\
Long time $\left(-20^{\circ} \mathrm{C}, 7 \mathrm{~d}\right)$ & 90.77 & 6.20 & 103.24 & 11.60 \\
\hline
\end{tabular}

TABLE 3: Rat plasma/serum levels of curcumin administered in different vehicles.

\begin{tabular}{|c|c|c|c|c|c|}
\hline Animal & Administration & Curcumin $(\mathrm{g} / \mathrm{kg})$ & Vehicle & $C_{\max }(\mu \mathrm{g} / \mathrm{mL})$ & $t_{\max }$ (hour) \\
\hline Diabetic rat ${ }^{\#}$ & Oral & 0.50 & Curcumin-enriched yoghurt $(0.5 \mathrm{~mL})$ & 0.060 & 0.25 \\
\hline Diabetic rat ${ }^{\#}$ & Intravenous & 0.01 & Curcumin in DMSO $(0.5 \mathrm{~mL} / \mathrm{kg})$ & 3.140 & 0.08 \\
\hline Normal rat [46] & Oral & 0.10 & Curcumin powder & 0.084 & 2.00 \\
\hline Normal rat [46] & Oral & 0.10 & Marketed CUR-500 capsules & 0.092 & 2.00 \\
\hline Normal rat [46] & Oral & 0.10 & Curcumin nanocrystal-loaded capsules & 0.041 & 0.50 \\
\hline Normal rat [47] & Oral & 0.05 & Curcumin aqueous suspension & 0.004 & 0.50 \\
\hline Normal rat [47] & Oral & 0.05 & Curcumin-loaded PLGA nanoparticles & 0.011 & 2.00 \\
\hline Normal rat [47] & Oral & 0.05 & Curcumin-loaded PLGA-PEG blend nanoparticles & 0.029 & 3.00 \\
\hline Normal rat $[48]$ & Oral & 0.10 & Curcumin nanoparticles & 0.260 & 2.00 \\
\hline Normal rat [48] & Oral & 0.25 & Curcumin + piperine $(0.01 \mathrm{~g} / \mathrm{kg})$ water suspension & 0.121 & 0.75 \\
\hline Normal rat $[48]$ & Oral & 0.25 & Curcumin suspension & 0.090 & 0.50 \\
\hline Normal rat [23] & Oral & 0.10 & Curcumin liposome dissolved in saline & 0.042 & 0.30 \\
\hline Normal rat [49] & Oral & 0.05 & Curcumin solubilized in Tween 80 & 292.000 & 0.25 \\
\hline Normal rat [49] & Oral & 0.05 & Curcumin loaded solid lipid nanoparticles & 14.290 & 0.50 \\
\hline Normal rat $[50]$ & Oral & 0.50 & $*$ & 0.060 & 0.68 \\
\hline Normal rat $[50]$ & Intravenous & 0.01 & * & 0.360 & $*$ \\
\hline Normal rat [51] & Oral & 1.00 & Curcumin phospholipid complex & 1.200 & 1.50 \\
\hline Normal rat [51] & Oral & 1.00 & $*$ & 0.500 & 0.75 \\
\hline Normal rat [52] & Oral & 0.34 & Curcumin phospholipid complex & 0.012 & 0.25 \\
\hline Normal rat [52] & Oral & 0.34 & Curcumin unformulated & 0.002 & 0.50 \\
\hline Normal rat [53] & Oral & 0.30 & Curcumin phospholipid complex & 0.600 & 2.33 \\
\hline Normal rat [53] & Oral & 0.10 & $*$ & 0.266 & 1.62 \\
\hline Normal rat [12] & Oral & 2.00 & Curcumin + piperine $(0.02 \mathrm{~g} / \mathrm{kg})$ water suspension & 1.800 & 1.29 \\
\hline Normal rat [12] & Oral & 2.00 & Curcumin aqueous suspension & 1.350 & 0.83 \\
\hline
\end{tabular}

\#This study.

${ }^{*}$ Not reported. $C_{\max }$ : peak plasma/serum concentration; $t_{\max }$ : time to reach peak plasma/serum concentration.

3.4. AKT Phosphorylation Levels and GLUT4 Content in Muscle Plasma Membrane after Long-Term Treatment of Diabetic Rats with Curcumin. Phosphorylation levels of AKT were significantly lower (approximately 50\%, $P<0.05$ ) in gastrocnemius muscles of diabetic rats treated with yoghurt (DYOG) when compared with NYOG or NC90 rats. There were no differences in the AKT phosphorylation levels between NYOG and NC90 rats (Figure 5(a)). On the other hand, after the glucose overload, the phosphorylation of AKT was significantly increased in gastrocnemius of diabetic rats treated with curcumin when compared with DYOG (3.7-fold, $P<0.01)$ and with NC90 $(82 \%, P<0.05)$ rats (Figure 5(a)).

After a glucose overload, the levels of GLUT4 in plasma membrane of NYOG, NC90, and DYOG rats were very similar (Figure 5(b)). However, GLUT4 content was increased in plasma membrane of gastrocnemius muscles of diabetic rats treated with curcumin (DC90) when compared with DYOG rats $(59 \%, P<0.05)$ and with NYOG and NC90 rats (45 and $38 \%$, resp., $P<0.05$ ) (Figure 5(b)).

\section{Discussion}

The values of $C_{\max }$ and $t_{\max }$ found in the present study after the oral administration of $500 \mathrm{mg} / \mathrm{kg}$ curcumin were similar to those of the study by Yang et al. [23], which administered to rats the same curcumin dose, although they did not mention the vehicle. The curcumin half-life in our study was $32.70 \pm$ 12.92 minutes (Table 4), while Yang and colleagues found it to be $44.5 \pm 7.5$ minutes [23]. Although the dose and the route of administration were similar between the studies, it 


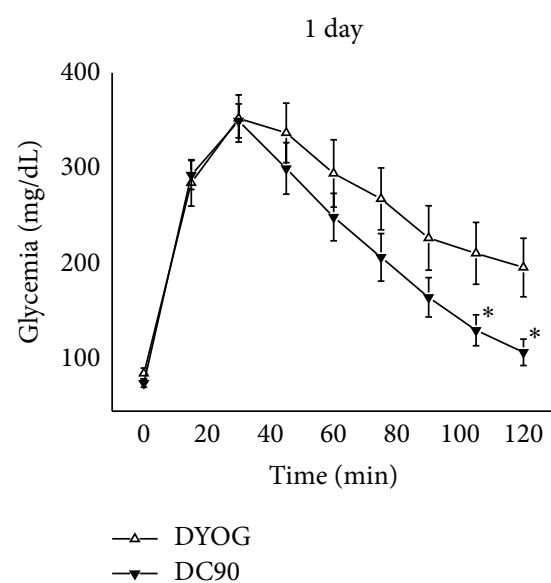

(a)

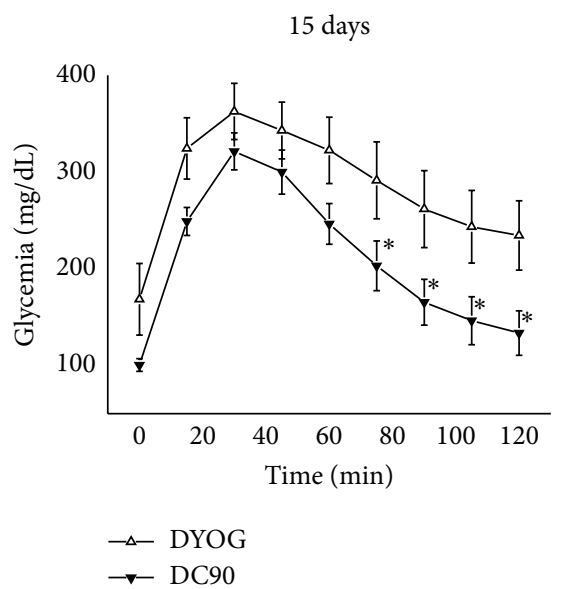

(c)
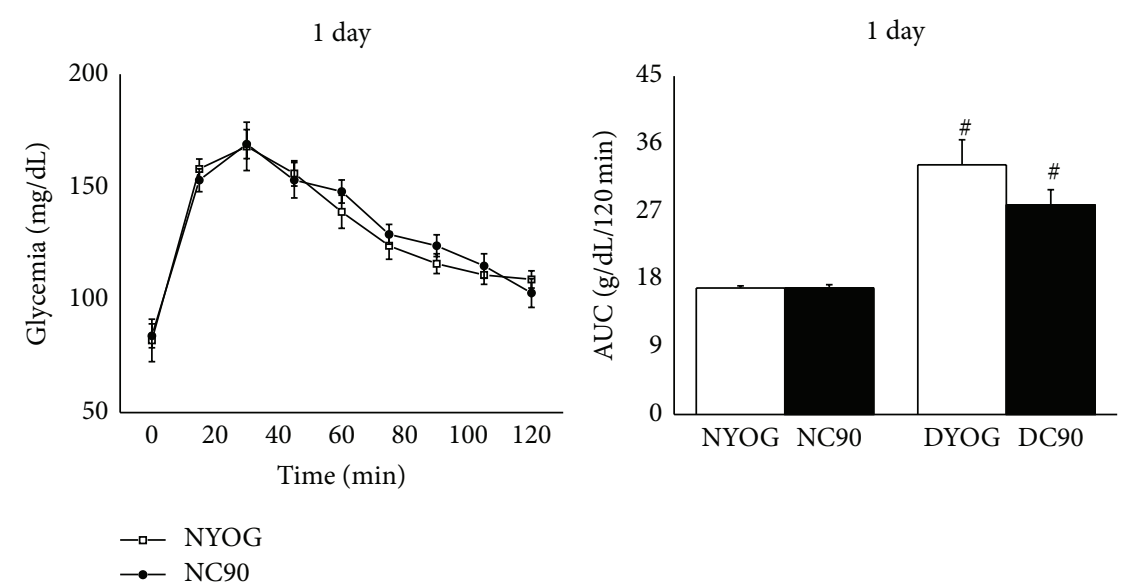

(b)
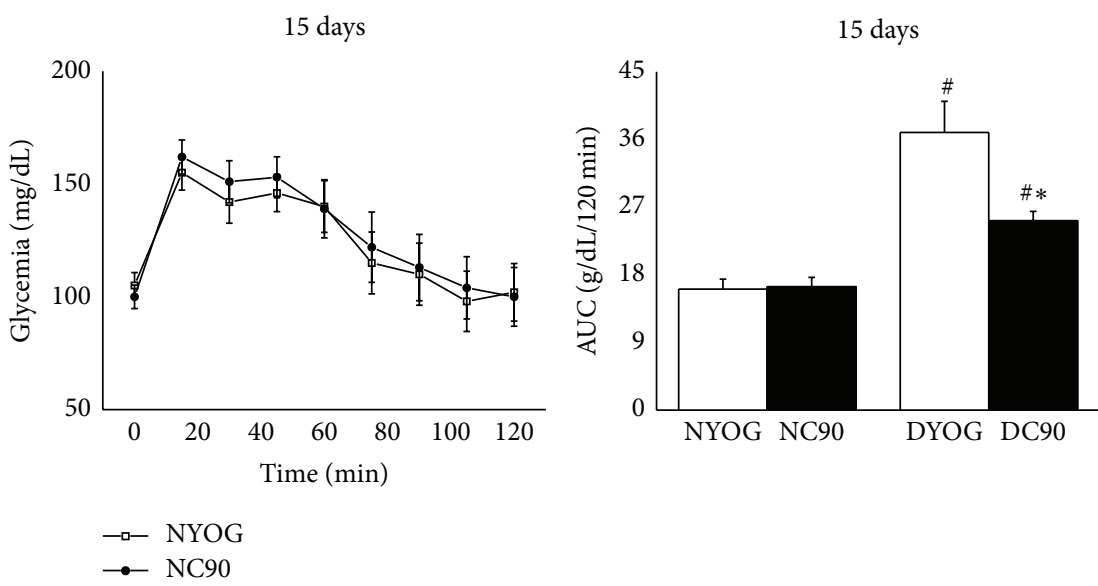

(d)

FIGURE 3: Oral glucose tolerance of normal and STZ-diabetic rats treated with curcumin incorporated in yoghurt. Glycemia levels before $(t=0)$ and after glucose overload in rats treated for 1 day ((a) diabetic; (b) normal) and for 15 days ((c) diabetic; (d) normal) with curcumin. The insets represent the AUC values (g/dL/120 min). Values are expressed as means $\pm \mathrm{SEM}, n=7-8$ per group. Differences between groups were analyzed with one-way ANOVA followed by Student-Newman-Keuls test $(P<0.05)$. \#: differences with NYOG and NC90; $*$ : differences with DYOG.

can be suggested that the slight difference in the half-life values may be due to differences in the animal's body weight, since Yang and colleagues used rats weighing between 280 and $320 \mathrm{~g}$, which could be influencing the $V_{d}$ and increasing the elimination half-life of curcumin.

There are several studies investigating the curcumin pharmacokinetic parameters; however there were some differences between them, such as the vehicle used for administration, dose, and animal body weight, which make the comparison difficult as can be seen in Table 3; these studies indicate clearly that levels of curcumin are not directly comparable. The $C_{\max }$ and AUC values obtained in the oral administration of curcumin were significantly lower than those found in the i.v. administration, and this fact suggests a low absorption and/or an increased hepatic first-pass metabolic biotransformation when curcumin is administered orally. The oral bioavailability of curcumin in rats was $0.47 \pm$ $0.12 \%$ (Table 4 ).
Several curcumin pharmacokinetic studies in the last decade showed low absorption and fast metabolism, leading to a decrease of its bioavailability. Thereby, curcumin plasma levels are extremely low; however it is highly efficient as a therapeutic agent. Therefore, it should be reasonable to assume that some of its biological activities are associated with curcumin metabolite(s). In addition, it has been shown that, after its absorption, curcumin undergoes conjugation to glucuronide or sulfate derivatives [24]. Zhongfa et al. [25] demonstrated that the major curcumin metabolites are curcumin-o-glucuronide, tetrahydrocurcumin (THC), and curcumin-o-sulfate. The curcumin absorption in rats occurs through intestinal cells and most of it is eliminated as curcumin glucuronide or sulfate [26].

Evidences about the biological activity of curcumin metabolites are increasing. THC is one of the most studied, which showed bioavailability higher than curcumin [27]. Studies have shown that THC has some biological activities, 


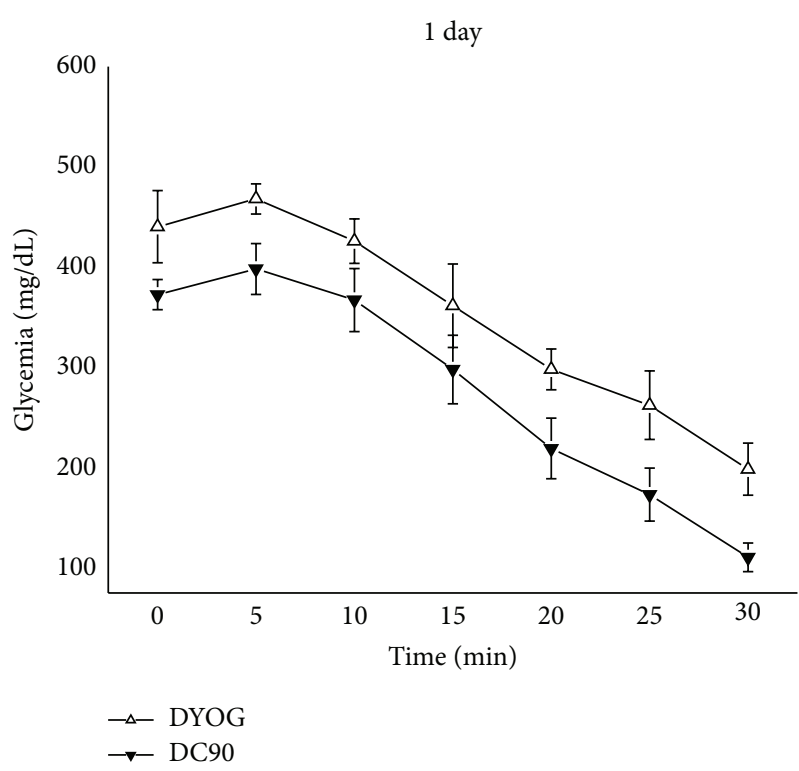

(a)

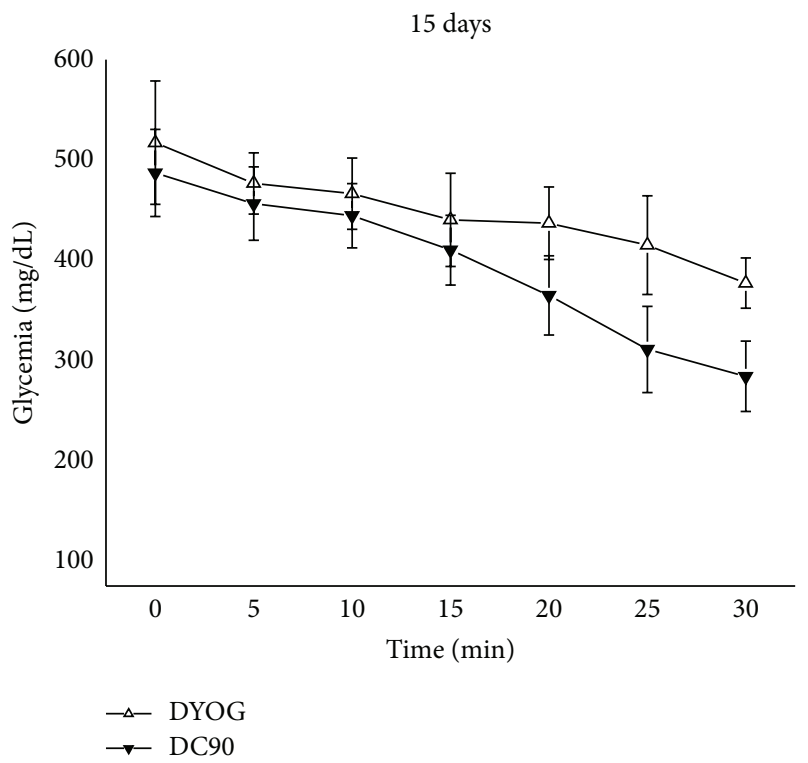

(c)

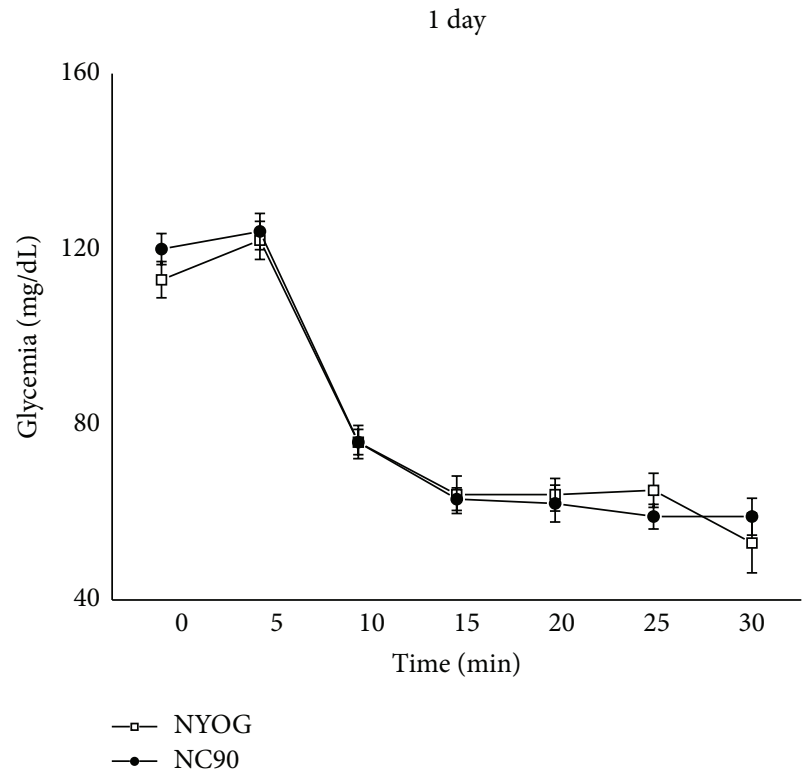

(b)

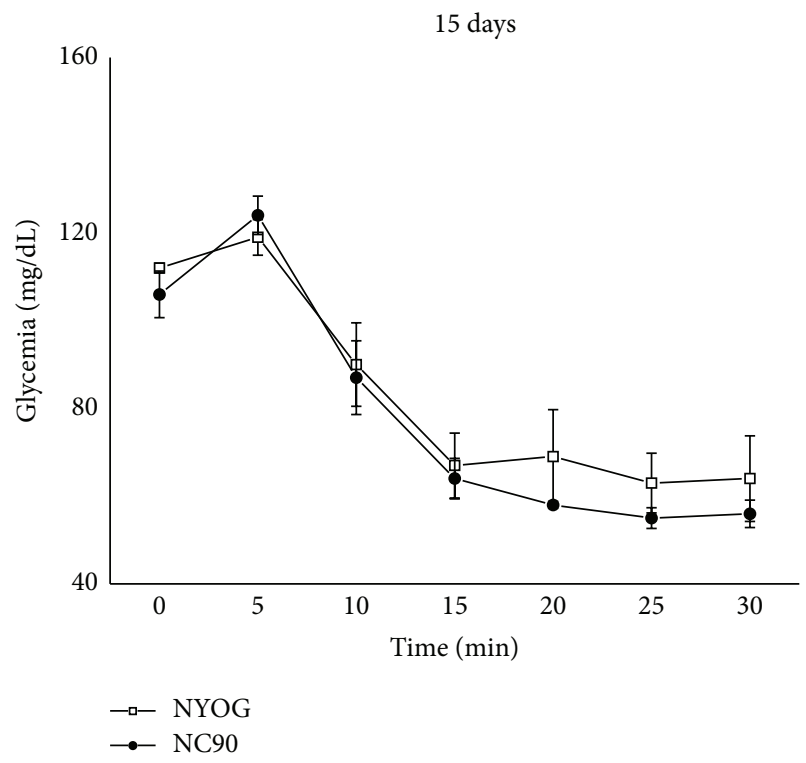

(d)

\begin{tabular}{lcccc}
\hline \multicolumn{4}{c}{$k_{\text {itt }}(\% / \mathrm{min})$} \\
& DYOG & DC90 & NYOG & NC90 \\
1 day & $0.040 \pm 0.003$ & $0.045 \pm 0.002$ & $0.038 \pm 0.004$ & $0.040 \pm 0.003$ \\
15 days & $0.012 \pm 0.002$ & $0.025 \pm 0.003^{*}$ & $0.040 \pm 0.005$ & $0.040 \pm 0.003$
\end{tabular}

FIGURE 4: Insulin sensitivity of normal and STZ-diabetic rats treated with curcumin incorporated in yoghurt. Glycemia levels after insulin administration in rats treated for 1 day ((a) diabetic; (b) normal) and for 15 days ((c) diabetic; (d) normal) with curcumin. The inserted table shows the $k_{\mathrm{itt}}$ values $(\% / \mathrm{min})$, which were calculated as percentage of the respective control group (DYOG or NYOG). Values are expressed as means \pm SEM, $n=7-8$ per group. Differences between groups were analyzed with one-way ANOVA followed by Student-Newman-Keuls test $(P<0.05) . *$ : differences with DYOG. 

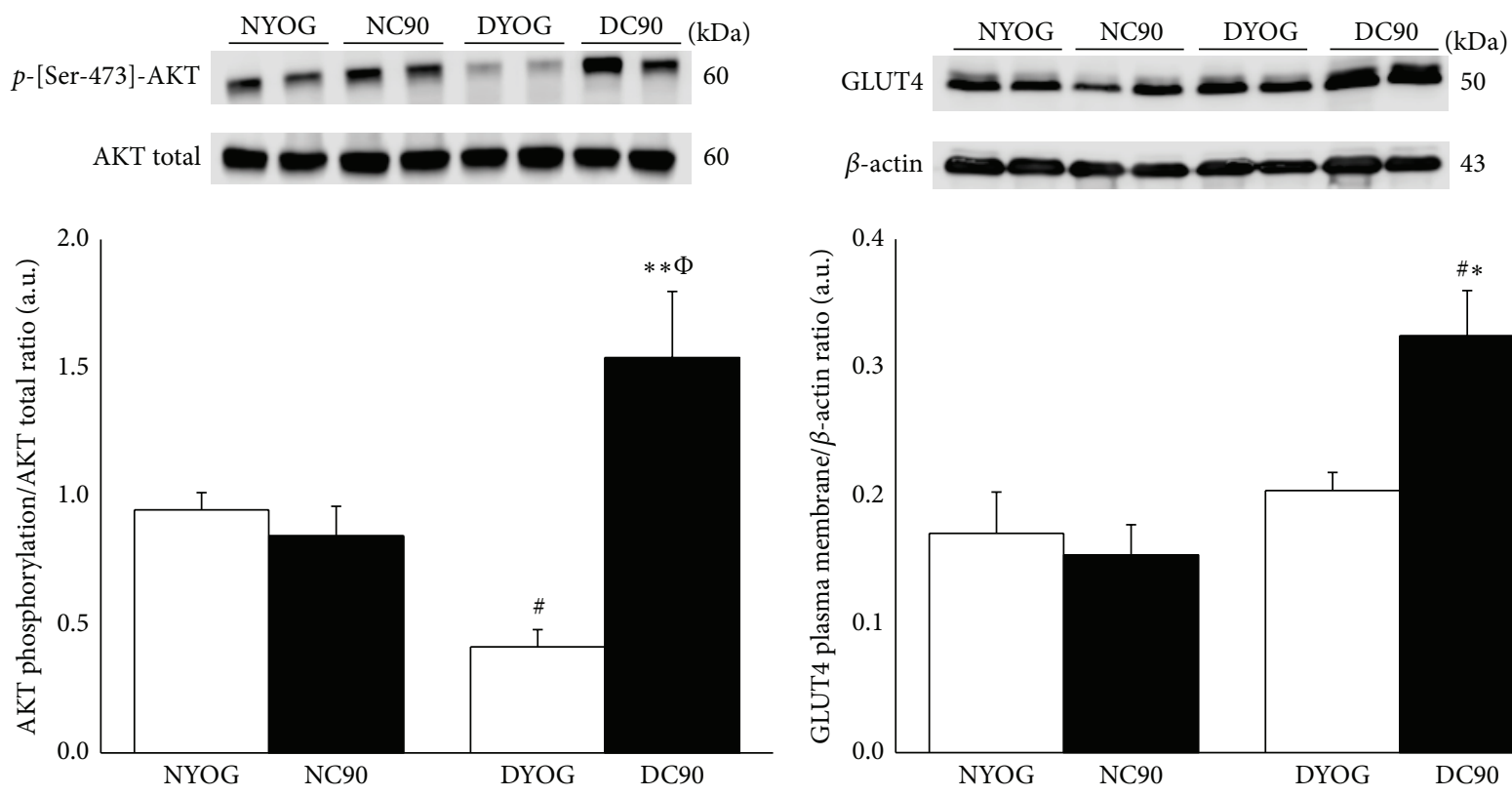

(a)

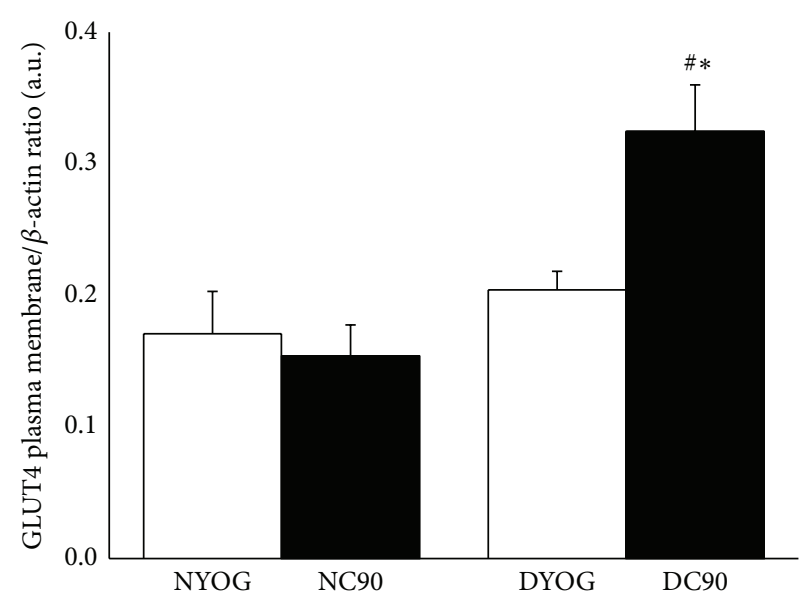

(b)

FIGURE 5: AKT activation (a) and plasma membrane GLUT4 content (b) in gastrocnemius muscles of normal and STZ-diabetic rats treated with curcumin incorporated in yoghurt for 15 days. AKT activation was evaluated as phosphorylation levels in Ser-473 residues. Results are expressed as means \pm SEM of the arbitrary units, $n=5-6$ per group. Differences between groups were analyzed with one-way ANOVA followed by Student-Newman-Keuls test. \# $(P<0.05)$ : differences with NYOG and NC90; $*(P<0.05)$ and $* *(P<0.01)$ : differences with DYOG; $\Phi(P<0.05)$ : differences between DC90 and NC90.

TABle 4: Pharmacokinetic parameters after oral $(500 \mathrm{mg} / \mathrm{kg})$ and i.v. administration $(10 \mathrm{mg} / \mathrm{kg})$ of curcumin to STZ-diabetic rats. Values are expressed as means $\pm \operatorname{SEM}(n=5)$.

\begin{tabular}{lcc}
\hline \multirow{2}{*}{ Pharmacokinetic parameters } & \multicolumn{2}{c}{ Administration route } \\
& Oral & i.v. \\
\hline$k_{\mathrm{el}}(1 / \mathrm{min})$ & $0.02 \pm 0.01$ & $0.08 \pm 0.02$ \\
$\mathrm{Half}-\mathrm{life}(\mathrm{min})$ & $32.70 \pm 12.92$ & $8.64 \pm 2.31$ \\
$\mathrm{AUC}_{0-t}(\mu \mathrm{g} / \mathrm{mL} / \mathrm{min})$ & $1.89 \pm 0.25$ & $12.27 \pm 2.75$ \\
$\mathrm{AUC}_{0-\infty}(\mu \mathrm{g} / \mathrm{mL} / \mathrm{min})$ & $2.97 \pm 0.79$ & $12.45 \pm 2.72$ \\
$\mathrm{Cl}(\mathrm{L} / \mathrm{kg} / \mathrm{min})$ & $0.85 \pm 0.24$ & $0.83 \pm 0.19$ \\
$V_{d}(\mathrm{~L} / \mathrm{kg})$ & $37.49 \pm 10.46$ & $10.63 \pm 4.10$ \\
$\mathrm{MRT}(\mathrm{min})$ & $55.41 \pm 20.19$ & $12.46 \pm 3.34$ \\
$k_{a}(1 / \mathrm{min})$ & $0.29 \pm 0.15$ & - \\
$C_{\max }(\mu \mathrm{g} / \mathrm{mL})$ & $0.06 \pm 0.01$ & $3.14 \pm 0.90$ \\
$t_{\max }(\mathrm{min})$ & $15.00 \pm 0.00$ & $5.00 \pm 0.00$ \\
$F(\%)$ & $0.47 \pm 0.12$ & 100 \\
\hline
\end{tabular}

$k_{\mathrm{el}}$ : elimination constant; half-life: time half-life; $\mathrm{AUC}_{0-t}:$ area under plasma concentration/time plot until the last quantifiable value; $\mathrm{AUC}_{0-\infty}$ : area under plasma concentration/time plot extrapolated to infinity; Cl: clearance; $V_{d}$ : volume of distribution; MRT: average mean residence time; $k_{a}$ : absorption constant; $C_{\max }$ : maximum concentration; $t_{\max }$ : time to reach $C_{\max } ; F$ : bioavailability.

such as anti-inflammatory [28], hepatoprotective [29], antidiabetic [27, 30], and antioxidant [31] activities; the most are higher when compared to curcumin effects.

The curcumin half-life was $32.70 \pm 12.92$ minutes (Table 4); that is, no curcumin should be bioavailable after
5.45 hours, because of the wash-out in ten half-lives [32]. Thus, it is possible to assume that one or more curcumin metabolites are responsible for its antidiabetic activity, since glycemia reduction in STZ-diabetic rats treated with curcumin incorporated in yogurt at intervals of 12 hours was observed [14].

Based on the aforementioned half-life considerations, the evaluation of changes in the glucose tolerance and insulin sensitivity of normal and diabetic rats after acute (1 day) and subchronic (15 days) treatments with curcumin-enriched yoghurt was performed. For this, we considered that the administration of glucose (OGTT) or insulin (ITT) would be carried out two hours after the curcumin administration, which means the elapsed time of approximately 4 halflives; at this time, the curcumin concentration should be in critical levels and so its metabolites would be present and at pharmacological levels [14]. Therefore, we could investigate the pharmacodynamic effects on glycemia at intervals of 2-4 hours and 2-2.5 hours for OGTT and ITT, respectively.

STZ administration to rats promotes pancreas beta cell destruction and decreases the insulin secretion; therefore, the hyperglycemia in STZ-diabetic rats appears within 12-48 hours after STZ injection [33]. Thus, the glucose intolerance of STZ-diabetic rats may be explained, at least in part, by their deficiency in secrete insulin after a glucose overload. Very low plasma insulin levels in STZ-diabetic rats after a glucose overload have been observed [34], which could explain our data related to the impaired glucose tolerance in rats with 4 and 19 days of diabetes, related to experiments carried out for 1 and 15 days, respectively (Figures 3(a) and 3(c)). 
Insulin resistance is defined as an attenuated biological response of tissues to physiological or elevated levels of insulin. According to our data, STZ-diabetic rats showed a diminished rate of glucose disappearance after insulin administration, in the 1st day of the experiment (4 days after STZ, Figure 4(a)), which was even impaired in the 15th day (19 days after STZ, Figure 4(c)). Evidences support the insulin resistance observed in STZ-diabetic animals, mainly characterized by a reduction in the tyrosine kinase activity of the insulin receptor (IR), despite the increased IR number $[35,36]$ and decrease in the AKT activation (phosphorylation in serine-473 residue) [37]. According to our data, diabetic rats after 19 days of the STZ administration and treated with yoghurt showed a profile compatible with insulin resistance, since the muscle AKT phosphorylation was lower than values of normal rats (Figure 5(a)). In addition to the direct disturbances in the insulin signaling of STZ-diabetic rats, the worsening in the insulin responsiveness observed with the progression of the diabetes may be also related to changes in the content of glucose transporters in skeletal muscles. Kahn et al. [38] observed that the levels of glucose transporters types 1 and 4 (GLUT1 and GLUT4) are progressively decreased in muscles of STZ-diabetic rats with the extent of the diabetes, although in this present study a reduction in GLUT4 content in muscle plasma membrane of diabetic rats (DYOG) in comparison with normal rats (NYOG) was not found, after a glucose overload (Figure 5(b)); these differences may be due to periods of diabetes studied (Kahn study: 7-14 days; present study: 19 days).

The similarity in the rate of glucose disappearance after a glucose overload (Figures 3(b) and 3(d)) or insulin administration as well as in the $k_{\text {itt }}$ values (Figures $4(\mathrm{~b})$ and 4 (d) and inserted table) of normal rats after 1 and 15 days of treatment represents that the tissue responsiveness to insulin is maintained in these animals over the experimental period. Both pancreas insulin secretion and peripheral insulin responsiveness are well-functioning in the correction of hyperglycemia states, so it is reasonable to understand the absence of effects of curcumin in the glucose tolerance and in the insulin sensitivity of nondiabetic rats. Also, AKT phosphorylation and GLUT4 plasma membrane levels are also similar between NYOG and NC90 rats (Figures 5(a) and 5(b)). These findings corroborate previous data from our laboratory, showing that even a chronic daily treatment (31 days) with curcumin-enriched yoghurt did not change the postprandial glycemia levels of normal rats [14].

Our results showed that one single administration of curcumin was not sufficient to improve the ability of STZdiabetic rats to reverse hyperglycemia. However, in the 1st day of curcumin treatment, it is interesting to note that these rats showed a fast decrease in the glycemia after 105 and 120 minutes of the glucose overload, when compared with untreated-diabetic rats (Figure 3(a)). This finding reiterates the pharmacokinetic data on the possibility of the beneficial effects of curcumin to be exerting by a metabolite(s), which need an additional time to reach the therapeutic levels and to control the glucose metabolism. In fact, it was observed that the treatment for 15 days with curcumin promoted a most evident benefit on glucose metabolism of diabetic rats, improving both the glucose tolerance (Figure 3(c)) and the insulin sensitivity (Figure 4(c) and inserted table). Long-term of a daily treatment with curcumin probably culminates in an increased permanence into the circulation of the curcumin metabolite(s), allowing the biological active compound(s) to exert its effects in a most pronounced way. Recent evidence of our laboratory reinforces the possibility of the antidiabetic activity of curcumin to be exerted by metabolite(s): Arcaro et al. [15] found that the treatment of STZ-diabetic rats with yoghurt enriched with $90 \mathrm{mg} / \mathrm{kg}$ curcumin and piperine did not increase $(20 \mathrm{mg} / \mathrm{kg}$ piperine) and even nullified ( $40 \mathrm{mg} / \mathrm{kg}$ piperine) the antidiabetic and antioxidant activities of curcumin. It is well known that piperine increases the bioavailability of many drugs and compounds, including curcumin, via inhibition of the activity of various metabolizing enzymes found in liver and intestine, such as aryl hydroxylases, N-demethylases, UDP-glucuronyltransferases, and cytochrome P450 3A4 [39, 40]. However, the inhibition of the curcumin biotransformation will not necessarily lead to an increase of its pharmacodynamic actions, and indeed adverse effects can be reached.

Corroborating the hypothesis that curcumin metabolite(s) has pivotal importance in determined biological activities when curcumin is administered orally, Neyrinck et al. [41] found that the coadministration of curcuma extract $(0.1 \%$ of curcumin) and $0.01 \%$ of white pepper (which contains piperine) to mice fed a high-fat (HF) diet did not promote any change in the glucose and lipid homeostasis, in comparison with nontreated HF mice. Besides, HF mice receiving these phytotherapics showed low levels of proinflammatory cytokines IL- 6 and TNF- $\alpha$ in subcutaneous adipose tissue in association with accumulation of THC; the authors suggested that this metabolite may be responsible for the antiinflammatory response.

The findings of the present study showed that diabetic rats treated for 15 days with curcumin incorporated in yoghurt had an increase in the AKT phosphorylation in gastrocnemius muscles (Figure 5(a)) in response to a glucose overload, which may explain the increased GLUT4 content (Figure 5(b)) in muscle plasma membranes of these rats, in comparison with diabetic rats treated only with yoghurt. Taken together, these results suggest that curcumin-enriched yoghurt increased the glucose uptake by skeletal muscles, which may account for the fast decrease in the hyperglycemia in DC90 rats after a glucose overload. Considering that the total GLUT4 content was not changed in muscles of diabetic rats by curcumin treatment (data not shown), it can be suggested that curcumin increased the GLUT4 translocation to plasma membrane, probably due to a direct AKT activation and/or by increase in the tissue responsiveness to insulin and/or by stimulating the pancreas insulin release. Although there are studies showing the ability of curcumin to promote AKT activation [42] and to increase the GLUT4 content in plasma membranes of skeletal muscles cells $[43,44]$, the possibility of these responses to be exerted by curcumin metabolites cannot be ruled out, which is corroborated by the effect of the coadministration of piperine $(40 \mathrm{mg} / \mathrm{kg})$ and curcumin $(90 \mathrm{mg} / \mathrm{kg})$ [15]. In addition, Murugan and collaborators [45] showed that erythrocytes from 
STZ-nicotinamide diabetic rats treated for 45 days with curcumin $(80 \mathrm{mg} / \mathrm{kg})$ or with THC $(80 \mathrm{mg} / \mathrm{kg})$ showed an increased ability for insulin-receptor binding when compared with cells from nontreated diabetic rats, which was associated with the antihyperglycemic effect of these compounds.

\section{Conclusion}

The present findings in the half-life of curcumin in plasma of diabetic rats $(\mathrm{PK})$ and in the temporal behavior in the glucose tolerance and insulin sensitivity assays after acute and subchronic treatments with curcumin-enriched yoghurt (PD) are inconsistent, which substantiate evidences for curcumin metabolite(s) as being responsible for the antidiabetic activity which may be related, at least in part, to an increase in skeletal muscle glucose uptake due to AKT activation leading to an enhancement in the plasma membrane GLUT4 content.

\section{Conflict of Interests}

The authors declare that there is no conflict of interests regarding the publication of this paper.

\section{Authors' Contribution}

Vânia Ortega Gutierres, Rosângela Gonçalves Peccinini, Amanda Martins Baviera, and Iguatemy Lourenço Brunetti participated in the research design. Vânia Ortega Gutierres, Michel Leandro Campos, Carlos Alberto Arcaro, and Renata Pires Assis performed the experiments. Michel Leandro Campos, Helen Mariana Baldan-Cimatti, Rosângela Gonçalves Peccinini, Silvia Paula-Gomes, Isis Carmo Kettelhut, and Amanda Martins Baviera contributed to new reagents or analytical tools. Vânia Ortega Gutierres, Michel Leandro Campos, Helen Mariana Baldan-Cimatti, Rosângela Gonçalves Peccinini, Silvia Paula-Gomes, Isis Carmo Kettelhut, Amanda Martins Baviera, and Iguatemy Lourenço Brunetti performed the data analysis. Vânia Ortega Gutierres, Michel Leandro Campos, Rosângela Gonçalves Peccinini, Silvia Paula-Gomes, Isis Carmo Kettelhut, Amanda Martins Baviera, and Iguatemy Lourenço Brunetti wrote or contributed to the writing of the paper.

\section{Acknowledgments}

The authors wish to thank the Conselho Nacional de Pesquisa e Desenvolvimento (CNPq), Faculdade de Ciências Farmacêuticas (FCFAr-UNESP), and Fundação de Amparo a Pesquisa do Estado de São Paulo (FAPESP) for the financial support. The authors are also grateful to Vivian Boter Bergamasco for the technical assistance.

\section{References}

[1] S. C. Gupta, G. Kismali, and B. B. Aggarwal, "Curcumin, a component of turmeric: from farm to pharmacy," BioFactors, vol. 39, no. 1, pp. 2-13, 2013.
[2] R. L. Thangapazham, A. Puri, S. Tele, R. Blumenthal, and R. K. Maheshwari, "Evaluation of a nanotechnology-based carrier for delivery of curcumin in prostate cancer cells," International Journal of Oncology, vol. 32, no. 5, pp. 1119-1123, 2008.

[3] L. M. Howells, J. Mahale, S. Sale et al., "Translating curcumin to the clinic for lung cancer prevention: evaluation of the preclinical evidence for its utility in primary, secondary, and tertiary prevention strategies," Journal of Pharmacology and Experimental Therapeutics, vol. 350, no. 3, pp. 483-494, 2014.

[4] W. Wongcharoen and A. Phrommintikul, "The protective role of curcumin in cardiovascular diseases," International Journal of Cardiology, vol. 133, no. 2, pp. 145-151, 2009.

[5] B. B. Aggarwal, "Targeting Inflammation-induced obesity and metabolic diseases by curcumin and other nutraceuticals," Annual Review of Nutrition, vol. 30, pp. 173-199, 2010.

[6] D.-W. Zhang, M. Fu, S.-H. Gao, and J.-L. Liu, "Curcumin and diabetes: a systematic review," Evidence-Based Complementary and Alternative Medicine, vol. 2013, Article ID 636053, 16 pages, 2013.

[7] M.-H. Pan, T.-M. Huang, and J.-K. Lin, "Biotransformation of curcumin through reduction and glucuronidation in mice," Drug Metabolism and Disposition, vol. 27, no. 4, pp. 486-494, 1999.

[8] S. K. Vareed, M. Kakarala, M. T. Ruffin et al., "Pharmacokinetics of curcumin conjugate metabolites in healthy human subjects," Cancer Epidemiology Biomarkers \& Prevention, vol. 17, no. 6, pp. 1411-1417, 2008.

[9] P. Anand, S. G. Thomas, A. B. Kunnumakkara et al., "Biological activities of curcumin and its analogues (Congeners) made by man and Mother Nature," Biochemical Pharmacology, vol. 76, no. 11, pp. 1590-1611, 2008.

[10] Y. Gao, Z. Li, M. Sun et al., "Preparation, characterization, pharmacokinetics, and tissue distribution of curcumin nanosuspension with TPGS as stabilizer," Drug Development and Industrial Pharmacy, vol. 36, no. 10, pp. 1225-1234, 2010.

[11] J. Cui, B. Yu, Y. Zhao et al., "Enhancement of oral absorption of curcumin by self-microemulsifying drug delivery systems," International Journal of Pharmaceutics, vol. 371, no. 1-2, pp. 148155, 2009.

[12] G. Shoba, D. Joy, T. Joseph, M. Majeed, R. Rajendran, and P. S. S. R. Srinivas, "Influence of piperine on the pharmacokinetics of curcumin in animals and human volunteers," Planta Medica, vol. 64, no. 4, pp. 353-356, 1997.

[13] S. Prasad, A. K. Tyagi, and B. B. Aggarwal, "Recent developments in delivery, bioavailability, absorption and metabolism of curcumin: the golden pigment from golden spice," Cancer Research and Treatment, vol. 46, no. 1, pp. 2-18, 2014.

[14] V. O. Gutierres, C. M. Pinheiro, R. P. Assis, R. C. Vendramini, M. T. Pepato, and I. L. Brunetti, "Curcumin-supplemented yoghurt improves physiological and biochemical markers of experimental diabetes," British Journal of Nutrition, vol. 108, no. 3, pp. 440-448, 2012.

[15] C. A. Arcaro, V. O. Gutierres, R. P. Assis et al., "Piperine, a natural bioenhancer, nullifies the antidiabetic and antioxidant activities of curcumin in streptozotocin-diabetic rats," PLoS ONE, vol. 9, no. 12, Article ID el13993, 2014.

[16] P. Trinder, "Determination of blood glucose using 4-amino phenazone as oxygen acceptor," Journal of Clinical Pathology, vol. 22 , no. 2 , p. $246,1969$.

[17] M. L. de Campos, H. M. Baldan-Cimatti, M. G. Davanço et al., "Pharmacokinetic profile of a new diclofenac prodrug without 
gastroulcerogenic effect," Drug Metabolism Letters, vol. 6, no. 4, pp. 235-241, 2013.

[18] K. Lundbaek, "Intravenous glucose tolerance as a tool in definition and diagnosis of diabetes mellitus," British Medical Journal, vol. 1, no. 5291, pp. 1507-1513, 1962.

[19] M. M. Bradford, "A rapid and sensitive method for the quantitation of microgram quantities of protein utilizing the principle of protein dye binding," Analytical Biochemistry, vol. 72, no. 1-2, pp. 248-254, 1976.

[20] S. Nishiumi and H. Ashida, "Rapid preparation of a plasma membrane fraction from adipocytes and muscle cells: application to detection of translocated glucose transporter 4 on the plasma membrane," Bioscience, Biotechnology, and Biochemistry, vol. 71, no. 9, pp. 2343-2346, 2007.

[21] U. K. Laemmli, "Cleavage of structural proteins during the assembly of the head of bacteriophage T4," Nature, vol. 227, no. 5259, pp. 680-685, 1970.

[22] H. Towbin, T. Staehelin, and J. Gordon, "Electrophoretic transfer of proteins from polyacrylamide gels to nitrocellulose sheets: procedure and some applications," Proceedings of the National Academy of Sciences of the United States of America, vol. 76, no. 9, pp. 4350-4354, 1979.

[23] K. Y. Yang, L. C. Lin, T. Y. Tseng, S. C. Wang, and T. H. Tsai, "Oral bioavailability of curcumin in rat and the herbal analysis from Curcuma longa by LC-MS/MS," Journal of Chromatography B: Analytical Technologies in the Biomedical and Life Sciences, vol. 853, no. 1-2, pp. 183-189, 2007.

[24] J.-K. Lin, M.-H. Pan, and S.-Y. Lin-Shiau, "Recent studies on the biofunctions and biotransformations of curcumin," BioFactors, vol. 13, no. 1-4, pp. 153-158, 2000.

[25] L. Zhongfa, M. Chiu, J. Wang et al., "Enhancement of curcumin oral absorption and pharmacokinetics of curcuminoids and curcumin metabolites in mice," Cancer Chemotherapy and Pharmacology, vol. 69, no. 3, pp. 679-689, 2012.

[26] A. Asai and T. Miyazawa, "Dietary curcuminoids prevent highfat diet-induced lipid accumulation in rat liver and epididymal adipose tissue," Journal of Nutrition, vol. 131, no. 11, pp. 29322935, 2001.

[27] K. Karthikesan, L. Pari, and V. P. Menon, "Combined treatment of tetrahydrocurcumin and chlorogenic acid exerts potential antihyperglycemic effect on streptozotocin-nicotinamideinduced diabetic rats," General Physiology and Biophysics, vol. 29, no. 1, pp. 23-30, 2010.

[28] Y. Nakamura, Y. Ohto, A. Murakami, T. Osawa, and H. Ohigashi, "Inhibitory effects of curcumin and tetrahydrocurcuminoids on the tumor promoter-induced reactive oxygen species generation in leukocytes in vitro and in vivo," Japanese Journal of Cancer Research, vol. 89, no. 4, pp. 361-370, 1998.

[29] L. Pari and D. R. Amali, "Protective role of tetrahydrocurcumin (THC) an active principle of turmeric on chloroquine induced hepatotoxicity in rats," Journal of Pharmacy \& Pharmaceutical Sciences, vol. 8, no. 1, pp. 115-123, 2005.

[30] L. Pari and P. Murugan, "Effect of tetrahydrocurcumin on blood glucose, plasma insulin and hepatic key enzymes in streptozotocin induced diabetic rats," Journal of Basic and Clinical Physiology and Pharmacology, vol. 16, no. 4, pp. 257274, 2005.

[31] K. Okada, C. Wangpoengtrakul, T. Tanaka, S. Toyokuni, K. Uchida, and T. Osawa, "Curcumin and especially tetrahydrocurcumin ameliorate oxidative stress-induced renal injury in mice," Journal of Nutrition, vol. 131, no. 8, pp. 2090-2095, 2001.
[32] P. L. Toutain and A. Bousquet-Mélou, "Plasma terminal halflife," Journal of Veterinary Pharmacology and Therapeutics, vol. 27, no. 6, pp. 427-439, 2004.

[33] S. Lenzen, "The mechanisms of alloxan- and streptozotocininduced diabetes," Diabetologia, vol. 51, no. 2, pp. 216-226, 2008.

[34] K. Kagami, H. Morita, K. Onda, T. Hirano, and K. Oka, "Protective effect of caffeine on streptozotocin-induced betacell damage in rats," Journal of Pharmacy and Pharmacology, vol. 60, no. 9, pp. 1161-1165, 2008.

[35] T. Kadowaki, M. Kasuga, Y. Akanuma, O. Ezaki, and F. Takaku, "Decreased autophosphorylation of the insulin receptor-kinase in streptozotocin-diabetic rats," The Journal of Biological Chemistry, vol. 259, no. 22, pp. 14208-14216, 1984.

[36] F. Giorgino, J.-H. Chen, and R. J. Smith, "Changes in tyrosine phosphorylation of insulin receptors and a 170,000 molecular weight nonreceptor protein in vivo in skeletal muscle of streptozotocin-induced diabetic rats: effects of insulin and glucose," Endocrinology, vol. 130, no. 3, pp. 1433-1444, 1992.

[37] J. J. Hulmi, M. Silvennoinen, M. Lehti, R. Kivelä, and H. Kainulainen, "Altered REDD1, myostatin, and Akt/mTOR/FoxO/MAPK signaling in streptozotocin-induced diabetic muscle atrophy," The American Journal of PhysiologyEndocrinology and Metabolism, vol. 302, no. 3, pp. E307-E315, 2012.

[38] B. B. Kahn, L. Rossetti, H. F. Lodish, and M. J. Charron, "Decreased in vivo glucose uptake but normal expression of GLUT1 and GLUT4 in skeletal muscle of diabetic rats," The Journal of Clinical Investigation, vol. 87, no. 6, pp. 2197-2206, 1991.

[39] C. K. Atal, R. K. Dubey, and J. Singh, "Biochemical basis of enhanced drug bioavailability by piperine: evidence that piperine is a potent inhibitor of drug metabolism," Journal of Pharmacology and Experimental Therapeutics, vol. 232, no. 1, pp. 258-262, 1985.

[40] K. Srinivasan, "Black pepper and its pungent principle-piperine: a review of diverse physiological effects," Critical Reviews in Food Science and Nutrition, vol. 47, no. 8, pp. 735-748, 2007.

[41] A. M. Neyrinck, M. Alligier, P. B. Memvanga et al., "Curcuma longa extract associated with white pepper lessens high fat dietinduced inflammation in subcutaneous adipose tissue," PLoS ONE, vol. 8, no. 11, Article ID e81252, 2013.

[42] Y.-T. Deng, T.-W. Chang, M.-S. Lee, and J.-K. Lin, "Suppression of free fatty acid-induced insulin resistance by phytopolyphenols in C2C12 mouse skeletal muscle cells," Journal of Agricultural and Food Chemistry, vol. 60, no. 4, pp. 1059-1066, 2012.

[43] T.-C. Cheng, C.-S. Lin, C.-C. Hsu, L.-J. Chen, K.-C. Cheng, and J.-T. Cheng, "Activation of muscarinic M-1 cholinoceptors by curcumin to increase glucose uptake into skeletal muscle isolated from Wistar rats," Neuroscience Letters, vol. 465, no. 3, pp. 238-241, 2009.

[44] L.-X. Na, Y.-L. Zhang, Y. Li et al., "Curcumin improves insulin resistance in skeletal muscle of rats," Nutrition, Metabolism and Cardiovascular Diseases, vol. 21, no. 7, pp. 526-533, 2011.

[45] P. Murugan, L. Pari, and C. A. Rao, "Effect of tetrahydrocurcumin on insulin receptor status in type 2 diabetic rats: studies on insulin binding to erythrocytes," Journal of Biosciences, vol. 33, no. 1, pp. 63-72, 2008.

[46] A. Liu, H. Lou, L. Zhao, and P. Fan, "Validated LC/MS/MS assay for curcumin and tetrahydrocurcumin in rat plasma and application to pharmacokinetic study of phospholipid complex of curcumin," Journal of Pharmaceutical and Biomedical Analysis, vol. 40, no. 3, pp. 720-727, 2006. 
[47] T. H. Marczylo, R. D. Verschoyle, D. N. Cooke, P. Morazzoni, W. P. Steward, and A. J. Gescher, "Comparison of systemic availability of curcumin with that of curcumin formulated with phosphatidylcholine," Cancer Chemotherapy and Pharmacology, vol. 60, no. 2, pp. 171-177, 2007.

[48] K. Maiti, K. Mukherjee, A. Gantait, B. P. Saha, and P. K. Mukherjee, "Curcumin-phospholipid complex: preparation, therapeutic evaluation and pharmacokinetic study in rats," International Journal of Pharmaceutics, vol. 330, no. 1-2, pp. 155163, 2007.

[49] V. Kakkar, S. Singh, D. Singla et al., "Pharmacokinetic applicability of a validated liquid chromatography tandem mass spectroscopy method for orally administered curcumin loaded solid lipid nanoparticles to rats," Journal of Chromatography B: Analytical Technologies in the Biomedical and Life Sciences, vol. 878, no. 32, pp. 3427-3431, 2010.

[50] J. LJi, Y. Jiang, J. Wen, G. Fan, Y. Wu, and C. Zhang, "A rapid and simple HPLC method for the determination of curcumin in rat plasma: assay development, validation and application to a pharmacokinetic study of curcumin liposome," Biomedical Chromatography, vol. 23, no. 11, pp. 1201-1207, 2009.

[51] J. Shaikh, D. D. Ankola, V. Beniwal, D. Singh, and M. N. V. R. Kumar, "Nanoparticle encapsulation improves oral bioavailability of curcumin by at least 9-fold when compared to curcumin administered with piperine as absorption enhancer," European Journal of Pharmaceutical Sciences, vol. 37, no. 3-4, pp. 223-230, 2009.

[52] N. M. Khalil, T. C. F. do Nascimento, D. M. Casa et al., "Pharmacokinetics of curcumin-loaded PLGA and PLGA-PEG blend nanoparticles after oral administration in rats," Colloids and Surfaces B: Biointerfaces, vol. 101, pp. 353-360, 2013.

[53] R. Ravichandran, "Pharmacokinetic study of nanoparticulate curcumin: oral formulation for enhanced bioavailability," Journal of Biomaterials and Nanobiotechnology, vol. 4, no. 3, pp. 291299, 2013. 


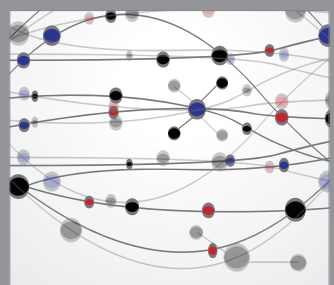

The Scientific World Journal
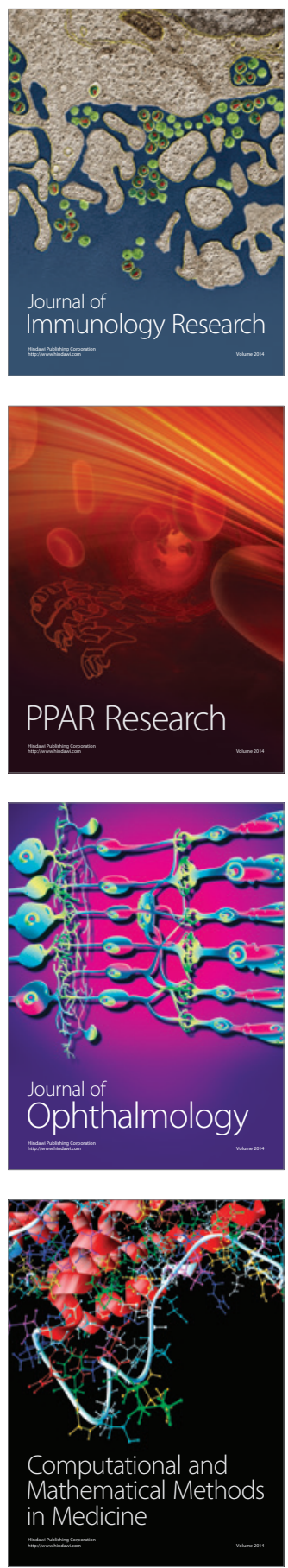

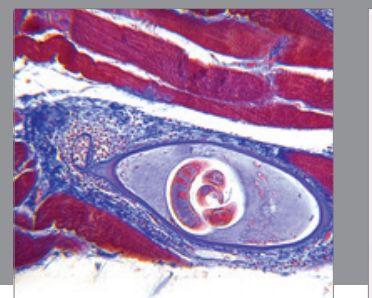

Gastroenterology

Research and Practice
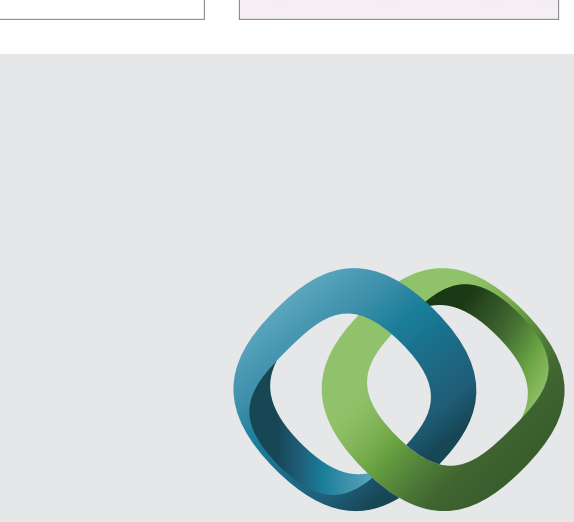

\section{Hindawi}

Submit your manuscripts at

http://www.hindawi.com
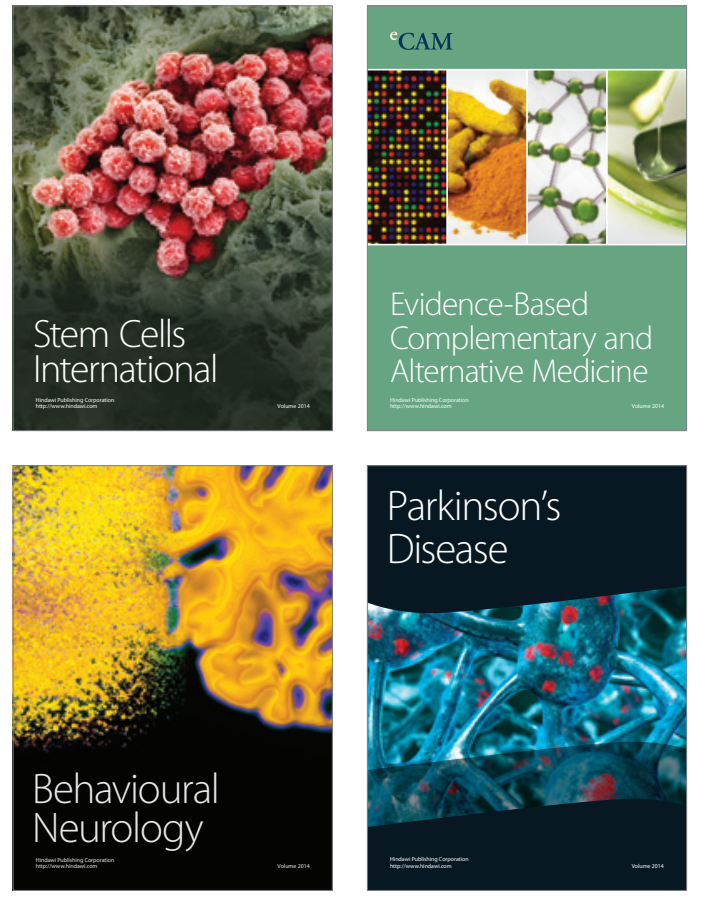
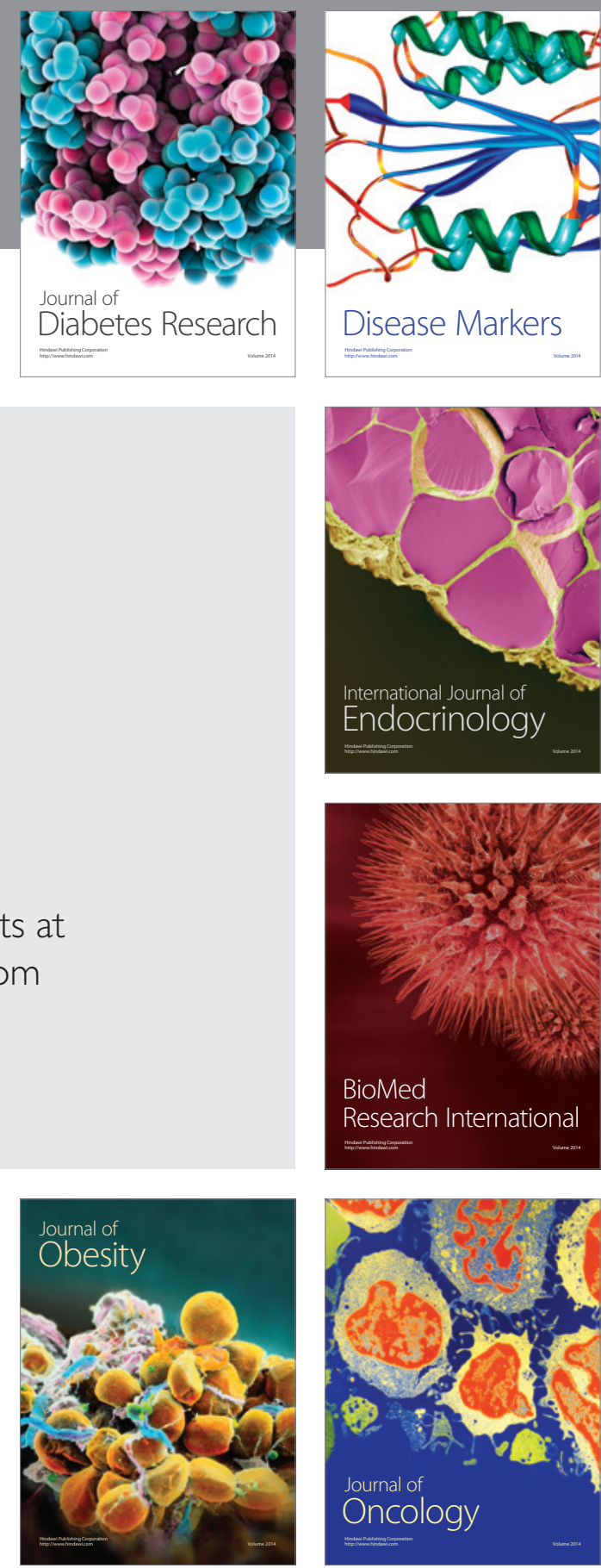

Disease Markers
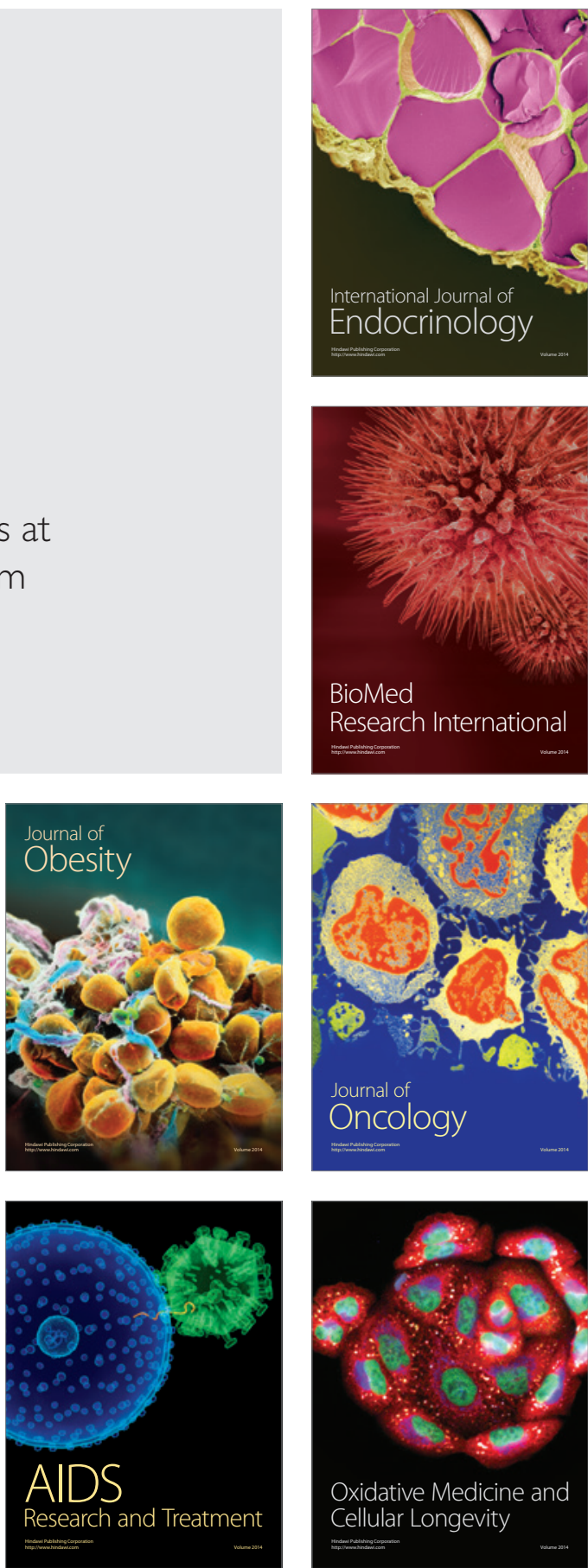